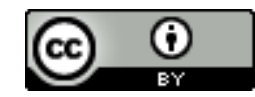

Esta obra está sob o direito de Licença Creative Commons Atribuição 4.0 Internacional.

\title{
OTIMIZAÇÃO EM REDES DE DISTRIBUIÇÃO HIDRÁULICAS
}

\author{
Ana Gabrielly Morais Silva ${ }^{1}$ \\ Andreza Leticia da Silva Santos Torres ${ }^{2}$ \\ Gilvan de Souza Ramos ${ }^{3}$ \\ João Vinícius Bezerra Lima ${ }^{4}$ \\ Michell Araújo de Souza ${ }^{5}$ \\ Rafaela Ribeiro de Oliveira ${ }^{6}$
}

\section{RESUMO}

O objetivo desse artigo foi realizar uma pesquisa bibliográfica com o intuito de demostrar, através de comparação de dados, a importância da elaboração de projetos de redes de distribuição de água de forma geral buscando otimização dos recursos hídricos, boa relação custo benefício e que estejam de acordo com as normatizações técnicas vigentes. A perda de carga em tubulações hidráulicas é uma importante variável para o dimensionamento de sistemas de transportes otimizados, assim, se torna obrigatório o estudo dessa variável no dimensionamento de redes de distribuição de abastecimento de águas. O presente trabalho está pautado na seguinte pergunta norteadora: quais as principais considerações, elencadas por diferentes autores, relacionadas a redução das perdas de carga em redes de distribuição de abastecimento na busca de otimização e da melhor relação custo benefício na sua implantação e operação? Foram buscados artigos científicos produzidos nos últimos cinco anos relacionados a temática na biblioteca Periódicos Capes utilizando uma forma estruturada de busca por meio de uma revisão sistemática integrativa. A análise dos artigos selecionados permitiu a criação de categorias que subsidiaram discussão dos principais pontos a serem considerados nos projetos redes de distribuição de abastecimento na busca de otimização. Conclui-se que, no projeto de dimensionamento hidrossanitário é fundamental o cômputo detalhado das perdas de carga distribuídas e localizadas, assim como, a adequação de todos os parâmetros hidráulicos para que não haja sub ou superdimensionamento no sistema e, que isso, não venha ocasionar problemas na relação custo benefício nem problemas futuros ao projeto.

Palavras-chave: Instalações prediais. Abastecimento. Dimensionamento.

\footnotetext{
1 anagabyms@hotmail.com

2 andrezals20@gmail.com

3 gil-ramos@outlook.com

4 joaovinicius1915@hotmail.com

5 michel0288@hotmail.com

${ }^{6}$ rafaelaribeiro.oliv@gmail.com
} 


\section{INTRODUÇÃO}

As perdas de cargas são comuns nas redes de distribuição de abastecimento (RDA), devido a vários possíveis meios que causam a variação de pressão e diâmetro interno nos tubos, além da rugosidade que influencia diretamente no fator de atrito entre o fluido e a tubulação.

A otimização das RDA de um determinado local se constitui como ferramentas de redução das perdas de cargas e adequação de parâmetros hidráulicos como subsídio para o dimensionamento de redes de distribuição de abastecimento (MORAIS, CAVALCANTE e ALMEIDA, 2010; SILVA et al., 2020). Os mesmos autores ressaltam que a utilização dessa ferramenta é fundamental para as cidades em desenvolvimento, haja vista que essas, necessitam a todo momento de ampliações das redes. A flexibilidade do projeto é um importante parâmetro a ser considerado no projeto de concepção de redes de distribuição de abastecimento (SILVA, 2016).

Os sistemas de abastecimento de águas - SAA, em sua totalidade, devem garantir as suas economias três características fundamentais, a saber, quantidade de água conforme a demanda de projeto, padrões de potabilidade para atividade que foi projetado e regularidade de abastecimento (BRASIL, 2017).

Segundo Silva et al. (2020) e Pinnto et al. (2017) a utilização de softwares e aplicativos facilitam o dimensionamento e proporcionam a otimização das RDA, balanceando o custo da implantação da tubulação e o tempo de vida útil dos materiais empregados.

Segundo os mesmos autores, esse procedimento é de suma importância e a combinação ótima de diâmetros para atender as especificações de abastecimento que satisfaçam o público familiar, comercial e industrial da cidade do projeto em questão, as insatisfações dos consumidores serão mínimas e respondidas com mais rapidez, pois será mais fácil detectar as fontes dos problemas. Os principais pontos a serem observados ao fazer a otimização da RDA (rede de distribuição de água) são: satisfação da população, impactos ambientais e custos de implantação e operacionais.

O dimensionamento de um SAA deve ser realizado com um alcance que contemple a projeção populacional, ou seja, a demanda de consumo, e para que seu funcionamento seja pleno em termos técnicos, evitando assim, os reparos exagerados. 
O presente trabalho está pautado na seguinte pergunta norteadora: quais as principais considerações, elencadas por diferentes autores, relacionadas a redução das perdas de carga em redes de distribuição de abastecimento na busca de otimização e da melhor relação custo benefício na sua implantação e operação?

A relevância do trabalho se dá pela necessidade de reunir trabalhos sobre a temática para que se possa definir as técnicas e estratégias de forma mais objetiva e prática sobre as principais considerações relacionadas a

\section{METODOLOGIA}

Primordialmente, foi realizada uma análise baseada em artigos científicos, com o intuito de identificar a melhor relação custo/benefício, a fim de otimizar, não só o processo de implementação das redes de distribuição, como também, as manutenções futuras.

A revisão de literatura foi do tipo sistemática integrativa, com critérios de inclusão artigos científicos publicados nos últimos cinco anos e exclusão de artigos fora da temática abordada. Os artigos foram buscados através das bibliotecas SciELO e Periódicos CAPES, utilizando os descritores combinados com o operador dimensionamento otimizado em redes de distribuição de abastecimento de águas.

Objetiva-se com o presente trabalho realizar uma revisão de literatura, assim como, discutir em categorias, sobre otimização e dimensionamento de redes de distribuição de abastecimento de águas para subsidiar engenheiros e profissionais da área de instalações hidráulicas a solucionar problemas referente a perdas de cargas e otimização do processo para tornar a vazão de forma regular e diminuir os problemas nas redes de distribuição de abastecimentos e consequentemente a insatisfação do consumidor.

booleano And, conforme descrito no Quadro 1.

As informações contidas nesse estudo, foram coletadas e armazenadas nos quadros abaixo de acordo com cada etapa, para formação do banco de dados. Os dados foram analisados com o objetivo de trazer maior entendimento sobre o assunto, sendo assim foram realizadas pesquisas exploratórias, descritivas e explicativas. 
Quadro 1 - Detalhamento das etapas da Revisão Sistemática Integrativa.

\begin{tabular}{|c|c|c|c|}
\hline ETAPA & $\begin{array}{c}\text { TÓPICOS } \\
\text { DE CADA } \\
\text { ETAPA }\end{array}$ & \multicolumn{2}{|c|}{ DETALHAMENTO DE CADA TÓPICO } \\
\hline \multirow[t]{12}{*}{$1^{\mathrm{a}}$} & Tema & \multicolumn{2}{|c|}{ Otimização em redes de distribuição hidráulicas } \\
\hline & $\begin{array}{c}\text { Pergunta } \\
\text { norteadora }\end{array}$ & \multicolumn{2}{|c|}{$\begin{array}{l}\text { O presente trabalho está pautado na seguinte pergunta norteadora: quais } \\
\text { as principais considerações, elencadas por diferentes autores, } \\
\text { relacionadas a redução das perdas de carga em redes de distribuição de } \\
\text { abastecimento na busca de otimização e da melhor relação custo } \\
\text { benefício na sua implantação e operação? }\end{array}$} \\
\hline & Objetivo geral & \multicolumn{2}{|c|}{$\begin{array}{l}\text { Fazer uma análise baseada em outros artigos, com o intuito de identificar } \\
\text { a melhor relação custo/benefício referente a implementação das redes } \\
\text { de distribuição hidráulicas, otimizando o processo de implementação } \\
\text { das redes de distribuição de água. }\end{array}$} \\
\hline & $\begin{array}{l}\text { Estratégias de } \\
\text { busca }\end{array}$ & \multicolumn{2}{|c|}{$\begin{array}{l}\text { 1. Cruzamento de descritores por meio do operador booleano AND; } \\
\text { 2. Uso de aspas nos politermos (descritor com mais de um termo) para } \\
\text { que a varredura de artigos científicos contemplasse o termo exato; } \\
\text { 3. Uso de descritores estruturados (codificação) no DECS ou MESH; } \\
\text { 4. Uso de metadados (filtros) nas bibliotecas virtuais; }\end{array}$} \\
\hline & $\begin{array}{c}\text { Bancos de } \\
\text { terminologias }\end{array}$ & DeCS & http://decs.bvs.br/ \\
\hline & \multirow{4}{*}{$\begin{array}{l}\text { Descritores } \\
\text { livres e } \\
\text { estruturados }\end{array}$} & Descritor & DeCS (Registro) \\
\hline & & Dimensionamento & 51614 \\
\hline & & Abastecimento & 15285 \\
\hline & & $\begin{array}{l}\text { Instalações } \\
\text { Prediais }\end{array}$ & 25321 \\
\hline & $\begin{array}{l}\text { String de } \\
\text { busca }\end{array}$ & \multicolumn{2}{|c|}{$\begin{array}{l}\text { Dimensionamento And Abastecimento; Abastecimento And } \\
\text { "Instalações prediais" }\end{array}$} \\
\hline & \multirow{2}{*}{$\begin{array}{l}\text { Bibliotecas } \\
\text { Virtuais }\end{array}$} & Biblioteca & Link \\
\hline & & $\begin{array}{l}\text { Scielo } \\
\text { Periódicos da CAF }\end{array}$ & $\begin{array}{l}\text { https://scielo.org/ } \\
\text { https://www-periodicos-capes-gov- } \\
\text { br.ezl.periodicos.capes.gov.br/index.php? }\end{array}$ \\
\hline \multirow[t]{3}{*}{$2^{\mathrm{a}}$} & $\begin{array}{l}\text { Período de } \\
\text { coleta dos } \\
\text { dados }\end{array}$ & & Novembro de 2020 \\
\hline & $\begin{array}{l}\text { Critérios de } \\
\text { inclusão }\end{array}$ & \multicolumn{2}{|c|}{$\begin{array}{l}\text { 6. Artigos (artigo científicos e free). } \\
\text { 7. Publicação (2015-2020). } \\
\text { 8. Engenharias } \\
\text { 9. Brasil } \\
\text { 10. Recursos hídricos } \\
\text { 11. Qualquer idioma }\end{array}$} \\
\hline & $\begin{array}{l}\text { Critérios de } \\
\text { exclusão }\end{array}$ & \multicolumn{2}{|c|}{$\begin{array}{l}\text { 5. Artigos que não contemplam a temática } \\
\text { 6. Artigos com mais de } 5 \text { anos de publicação }\end{array}$} \\
\hline $3^{a}$ & \multicolumn{3}{|c|}{$\begin{array}{lr}\text { Número de } & \text { trabalhos } \\
\text { selecionados } & \text { para } \\
\text { revisão sistemática } \\
\text { integrativa a partir da } \\
\text { leitura dos agentes } \\
\text { indexadores r das }\end{array}$} \\
\hline
\end{tabular}




\begin{tabular}{|l|l|l|}
\hline $4^{\text {a }}$ & $\begin{array}{l}\text { publicações (tema, } \\
\text { descrição, ementa). }\end{array}$ & \\
\hline & $\begin{array}{l}\text { Categorias obtidas com } \\
\text { a análiser dos } \\
\text { documentos rrados online } \\
\text { investigados } \\
\text { gratuitos e de livre } \\
\text { acesso }\end{array}$ & \\
\hline $5^{\text {a }}$ & $\begin{array}{l}\text { Análise, interpretação } \\
\text { e discussão dos } \\
\text { resultados }\end{array}$ & Ver em "Resultados e Discussão" \\
\hline $6^{\text {a }}$ & $\begin{array}{l}\text { Apresentação da da } \\
\text { revisão em formato de } \\
\text { artigo, o qual } \\
\text { contemple propostas } \\
\text { para estudos futuros }\end{array}$ & \\
\hline
\end{tabular}

Fonte: elaborada pelos autores.

\section{RESULTADOS}

Quadro 2 - Corresponde ao total de documentos disponíveis na Plataforma obtidos por string de busca.

\begin{tabular}{|l|c|c|c|c|}
\hline \multicolumn{1}{|c|}{ String de busca } & $\begin{array}{c}\text { Bases de } \\
\text { dados }\end{array}$ & $\begin{array}{c}\text { Total de } \\
\text { publicações } \\
\text { sem o filtro }\end{array}$ & $\begin{array}{c}\text { Publicações } \\
\text { disponíveis após } \\
\text { aplicar os filtros }\end{array}$ & $\begin{array}{c}\text { Publicações } \\
\text { aproveitadas na } \\
\text { Revisão Sistemática } \\
\text { Integrativa }\end{array}$ \\
\hline $\begin{array}{l}\text { Dimensionamento } \\
\text { And } \\
\text { Abastecimento; }\end{array}$ & $\begin{array}{c}\text { Periódicos da } \\
\text { Capes }\end{array}$ & 29 & 13 & 2 \\
\cline { 2 - 5 } & $\begin{array}{c}\text { Periódicos da } \\
\text { Capes }\end{array}$ & 86 & 37 & 2 \\
\hline $\begin{array}{l}\text { Abastecimento } \\
\text { And "Instalações } \\
\text { prediais" }\end{array}$ & Scielo & 1351 & 15 & 1 \\
\cline { 2 - 5 } & Scielo & 22 & 22 & 1 \\
\hline
\end{tabular}

Fonte: elaborada pelos autores.

Quadro 3- Descrição dos documentos (artigos) de acordo com os critérios de inclusão.

\begin{tabular}{|c|c|c|c|c|c|}
\hline $\begin{array}{c}\mathbf{N} \\
\mathbf{0}\end{array}$ & $\begin{array}{c}\text { Autor(a } \\
\text { ) }\end{array}$ & Tema & Link da publicação & $\begin{array}{c}\text { Data } \\
\text { de } \\
\text { public } \\
\text { ação }\end{array}$ & Conclusão \\
\hline 1 & $\begin{array}{l}\text { André } \\
\text { Luis } \\
\text { Mileo } \\
\text { Ferraiol } \\
\text { i Silva } \\
\text { André } \\
\text { Luiz } \\
\text { Amaran } \\
\text { te } \\
\text { Mesquit } \\
\text { a }\end{array}$ & $\begin{array}{l}\text { Simulação } \\
\text { do fator de } \\
\text { atrito para } \\
\text { o } \\
\text { escoamento } \\
\text { confinado } \\
\text { de caulim } \\
\text { com } \\
\text { diferentes } \\
\text { teores de } \\
\text { sólidos } \\
\text { pelo } \\
\text { modelo de }\end{array}$ & $\begin{array}{l}\text { https://www.scielo.br/scielo.php?script=sci } \\
\text { arttext\&pid=S1517- } \\
\text { 70762017000200422\&lang=pt }\end{array}$ & $\begin{array}{l}27 / 06 / \\
2017\end{array}$ & $\begin{array}{l}\text { As } \\
\text { suspensões } \\
\text { de caulim } \\
\mathrm{A}(65 \%), \\
\mathrm{B}(60 \%) \mathrm{e} \\
\mathrm{C}(55 \%) \\
\text { possuem boa } \\
\text { operacionalid } \\
\text { ade nas } \\
\text { tubulações de } \\
0,2 \text { e } 0,3 \\
\text { metros de } \\
\text { diâmetro } \\
\text { para toda a }\end{array}$ \\
\hline
\end{tabular}




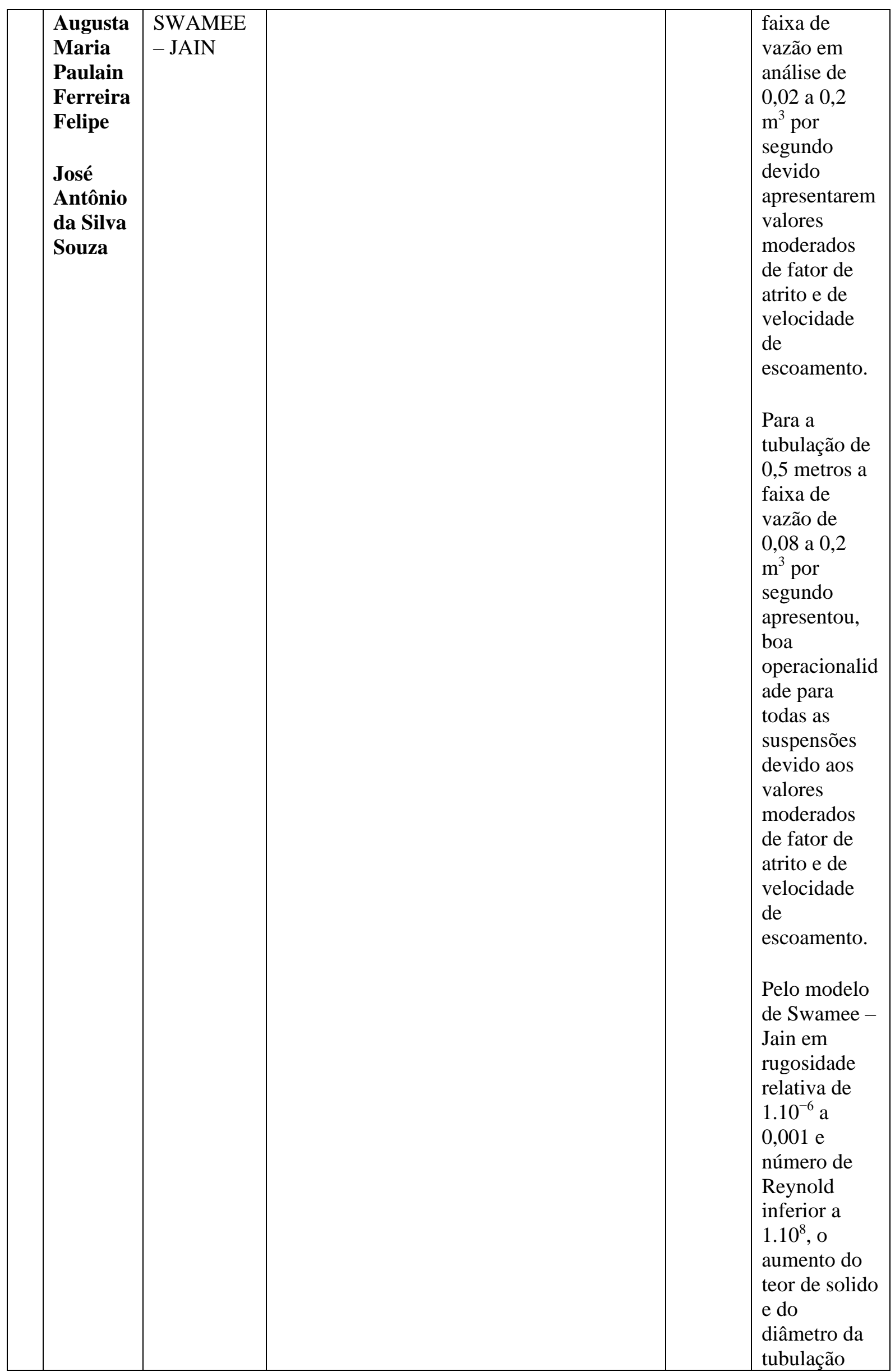




\begin{tabular}{|c|c|c|c|c|c|}
\hline & & & & & $\begin{array}{l}\text { para faixa } \\
\text { operacional } \\
\text { de vazão } \\
\text { contribui } \\
\text { para o } \\
\text { aumento do } \\
\text { fator de atrito } \\
\text { no } \\
\text { escoamento } \\
\text { confinado de } \\
\text { caulim em } \\
\text { tubulação de } \\
\text { ferro } \\
\text { galvanizado } \\
\text { possibilitand } \\
\text { o o projeto e } \\
\text { o } \\
\text { acompanham } \\
\text { ento do } \\
\text { escoamento } \\
\text { de caulim de } \\
\text { forma mais } \\
\text { precisa, } \\
\text { contribuindo } \\
\text { para a } \\
\text { diminuição } \\
\text { do consumo } \\
\text { energético no } \\
\text { setor } \\
\text { mineral. }\end{array}$ \\
\hline 2 & $\begin{array}{l}\text { Marcos } \\
\text { Rodrigu } \\
\text { es } \\
\text { Pinnto } \\
\text { Marco } \\
\text { Aurélio } \\
\text { Holanda } \\
\text { de Castr } \\
\text { o } \\
\text { João } \\
\text { Marcelo } \\
\text { Costa } \\
\text { Barbosa } \\
\text { José } \\
\text { Valmir } \\
\text { Farias } \\
\text { Maia } \\
\text { Júnior }\end{array}$ & $\begin{array}{l}\text { Dimension } \\
\text { amento } \\
\text { econômico } \\
\text { otimizado } \\
\text { de redes de } \\
\text { distribuição } \\
\text { de água } \\
\text { consideran } \\
\text { do custos } \\
\text { de } \\
\text { manutençã } \\
\text { o }\end{array}$ & $\begin{array}{l}\text { https://www.scielo.br/scielo.php?script=sci } \\
\text { arttext\&pid=S1413- } \\
\text { 41522017000100145\&lang=pt }\end{array}$ & $\begin{array}{l}27 / 10 / \\
2016\end{array}$ & $\begin{array}{l}\text { As obras de } \\
\text { saneamento } \\
\text { são } \\
\text { normalmente } \\
\text { executadas } \\
\text { por } \\
\text { governos. A } \\
\text { administraçã } \\
\text { o pública se } \\
\text { norteia por } \\
\text { princípios } \\
\text { específicos } \\
\text { para a sua } \\
\text { gestão, entre } \\
\text { eles, o } \\
\text { princípio da } \\
\text { eficiência, } \\
\text { inserido pela } \\
\text { Emenda } \\
\text { Constitucion } \\
\text { al número } \\
19, \text { de } 4 \text { de } \\
\text { junho de } \\
\text { 1998. No } \\
\text { entanto, essa }\end{array}$ \\
\hline
\end{tabular}




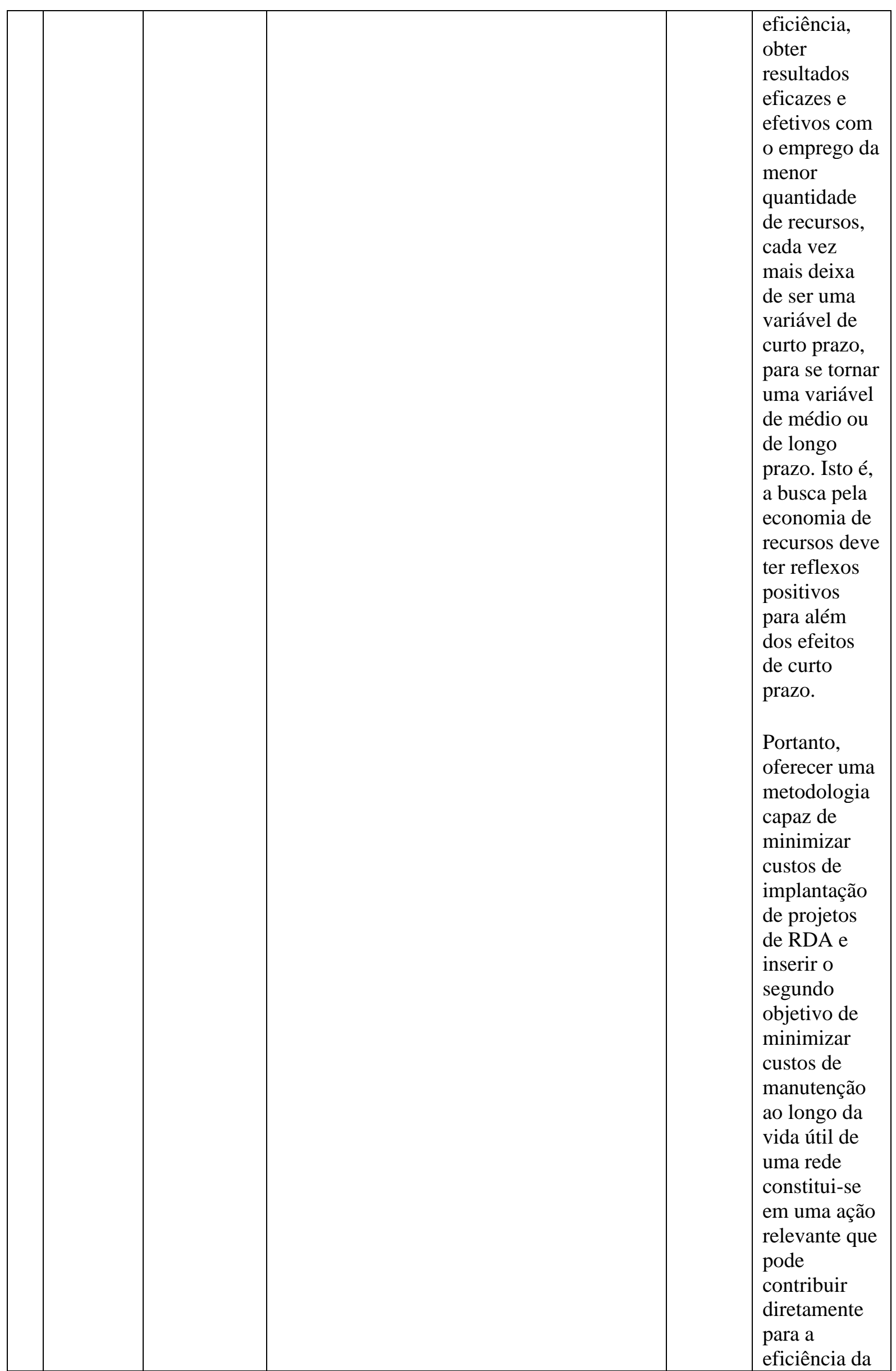




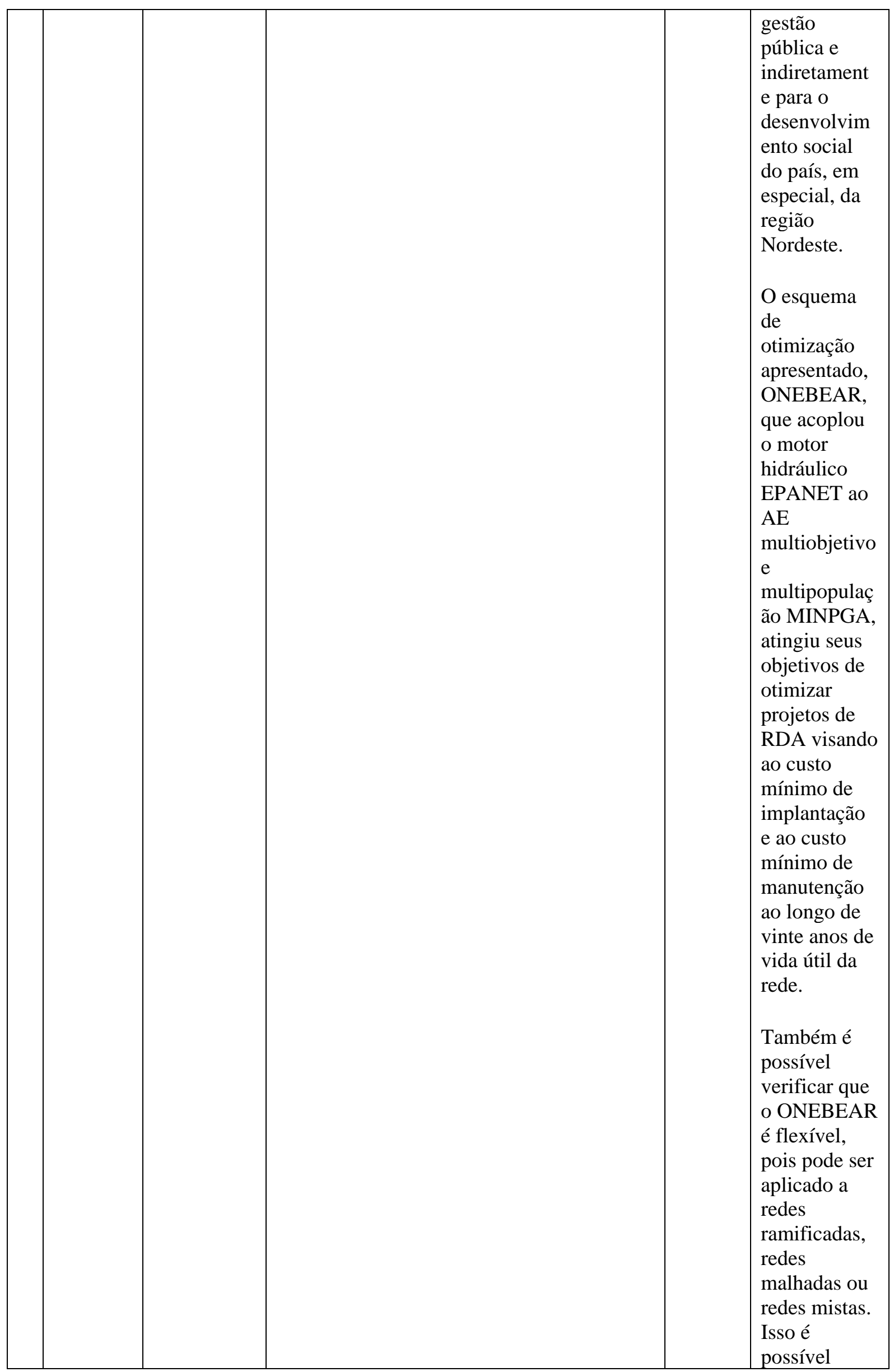




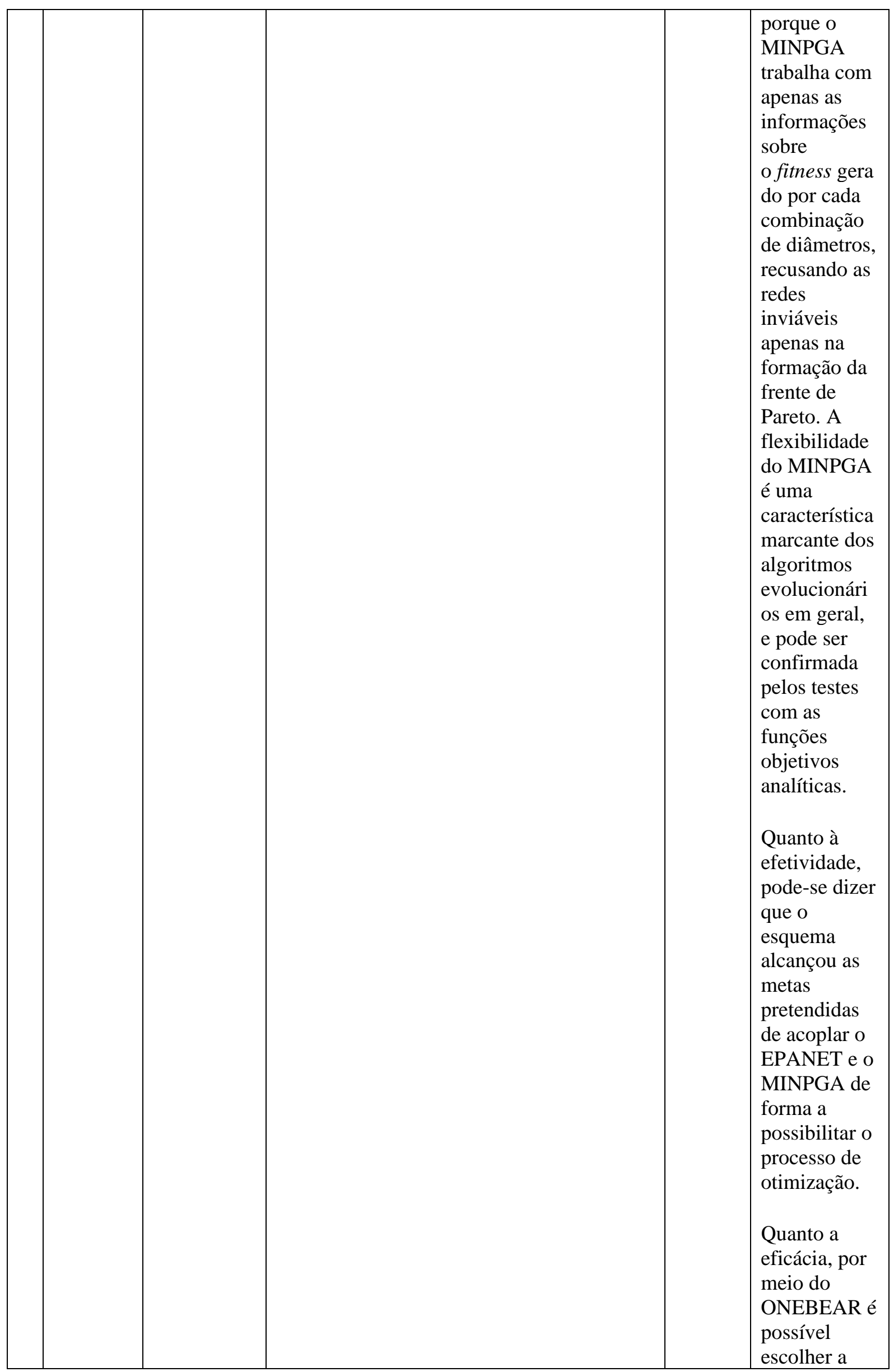




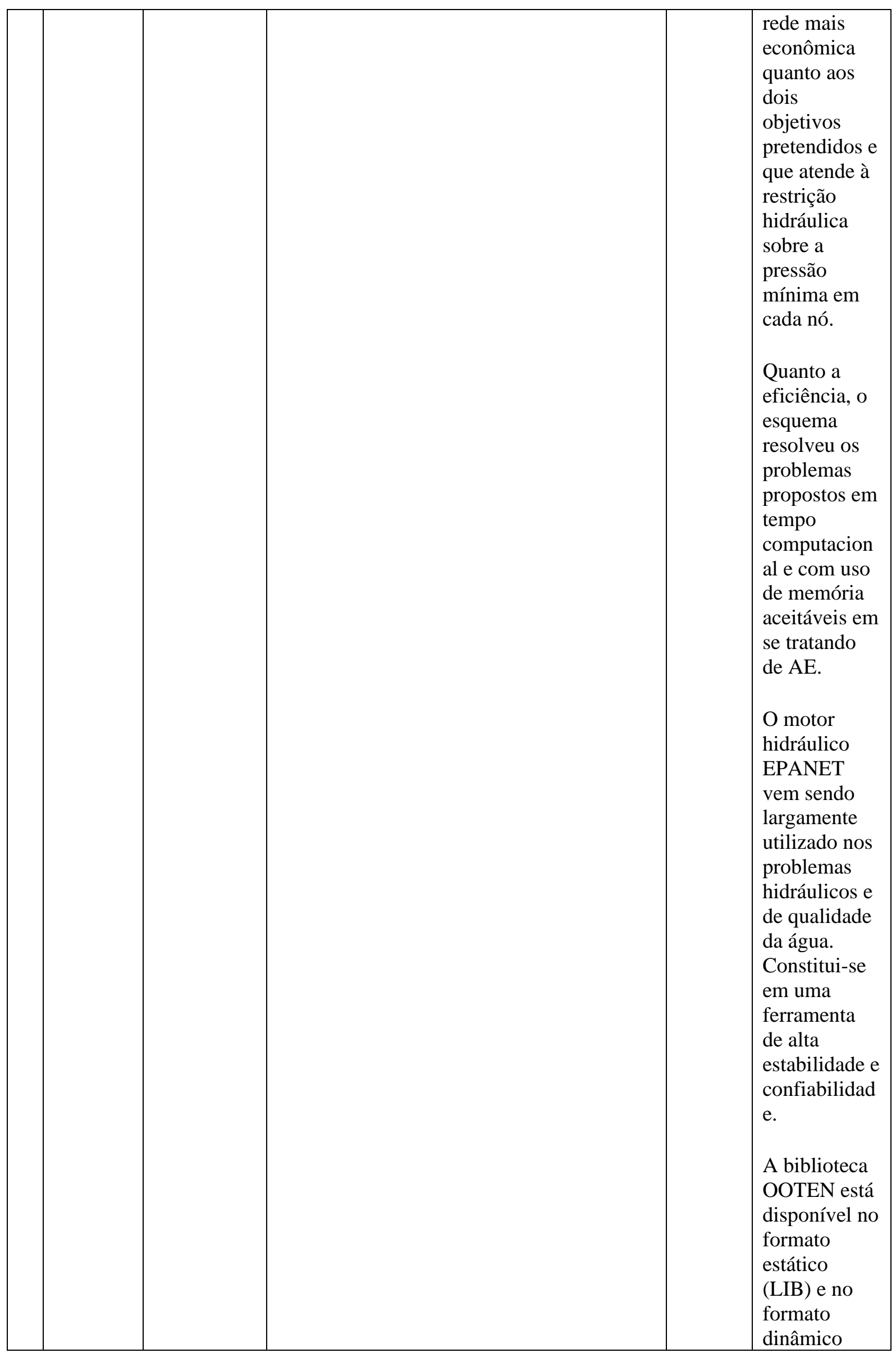




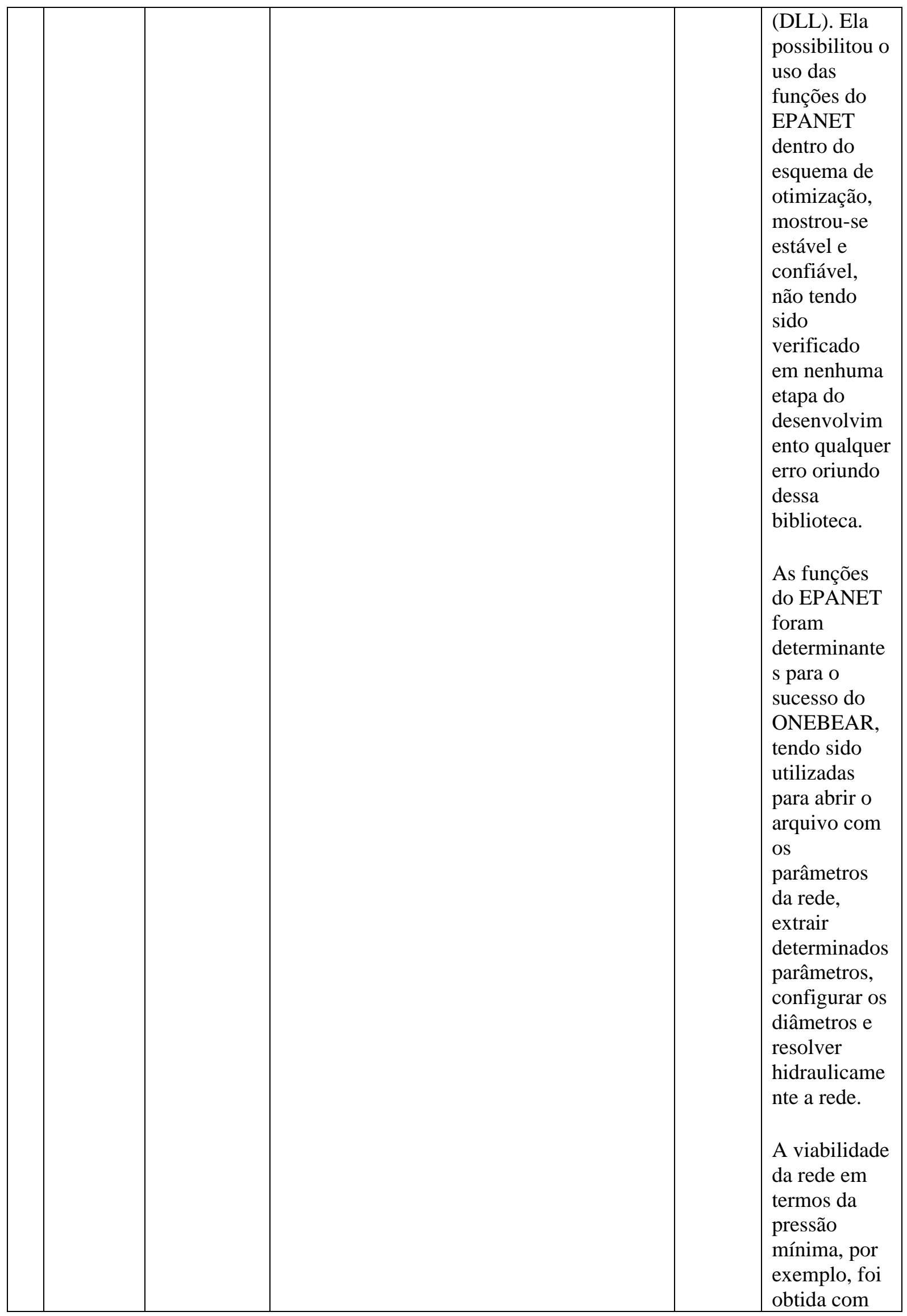




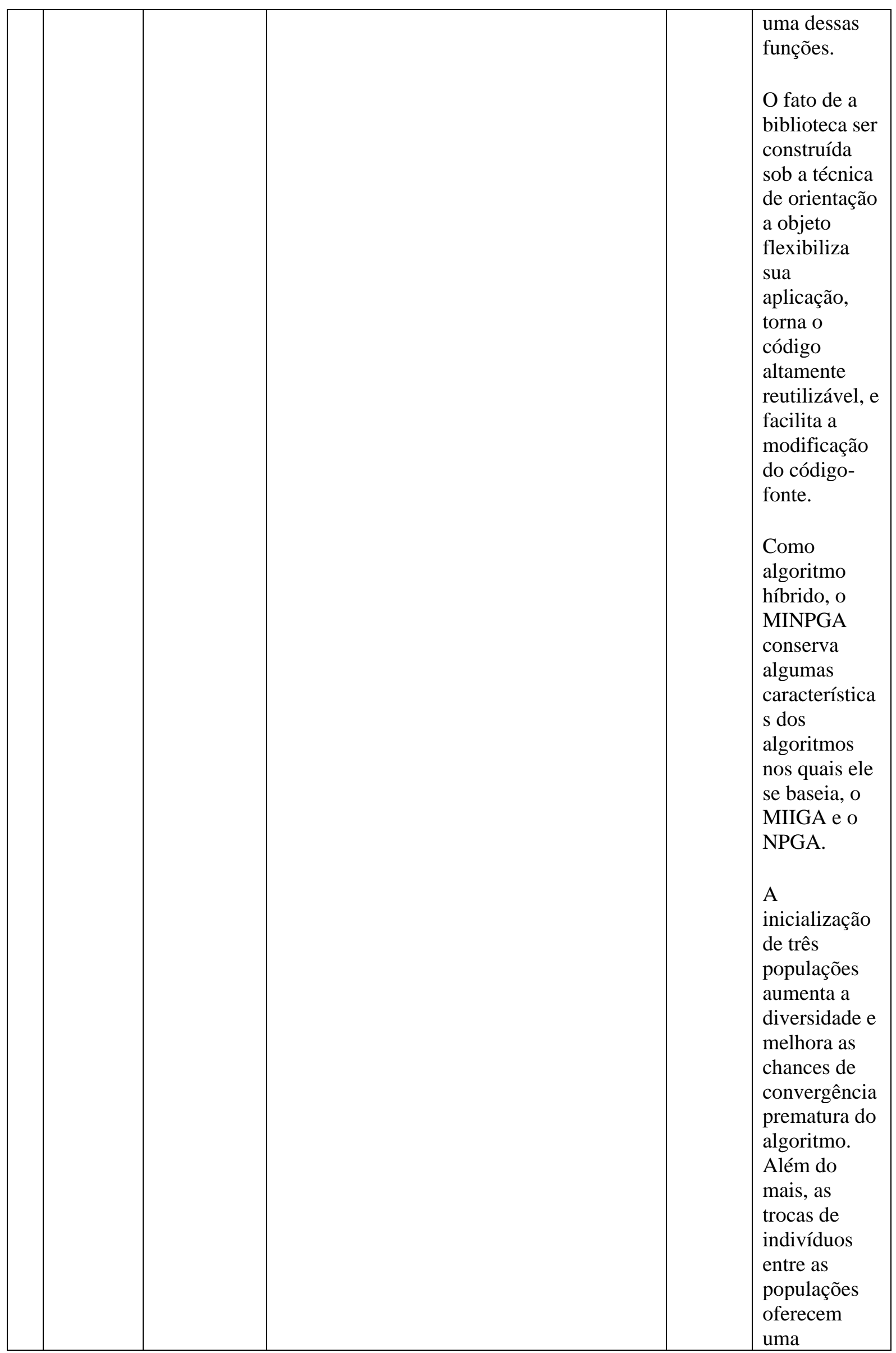




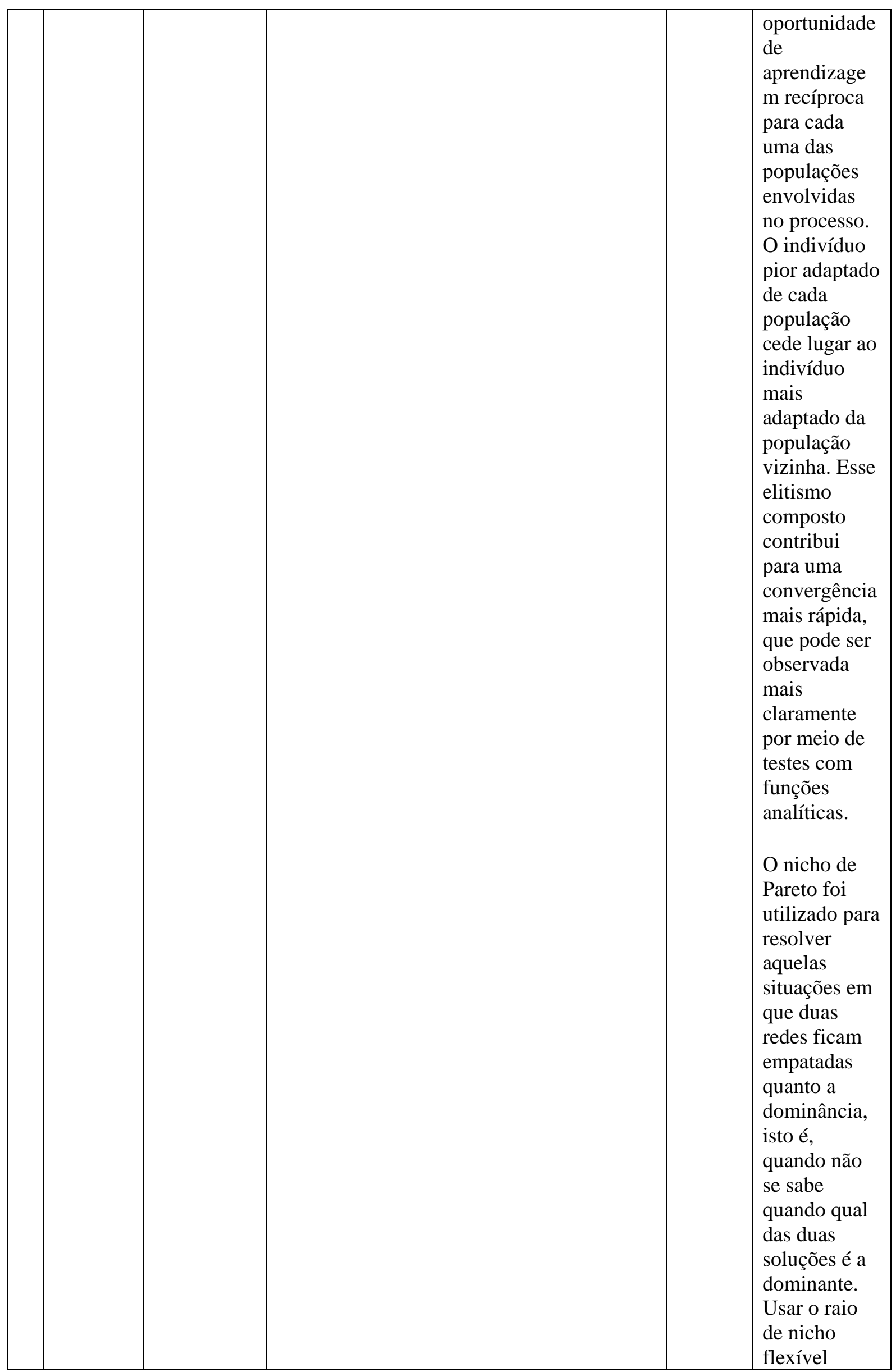




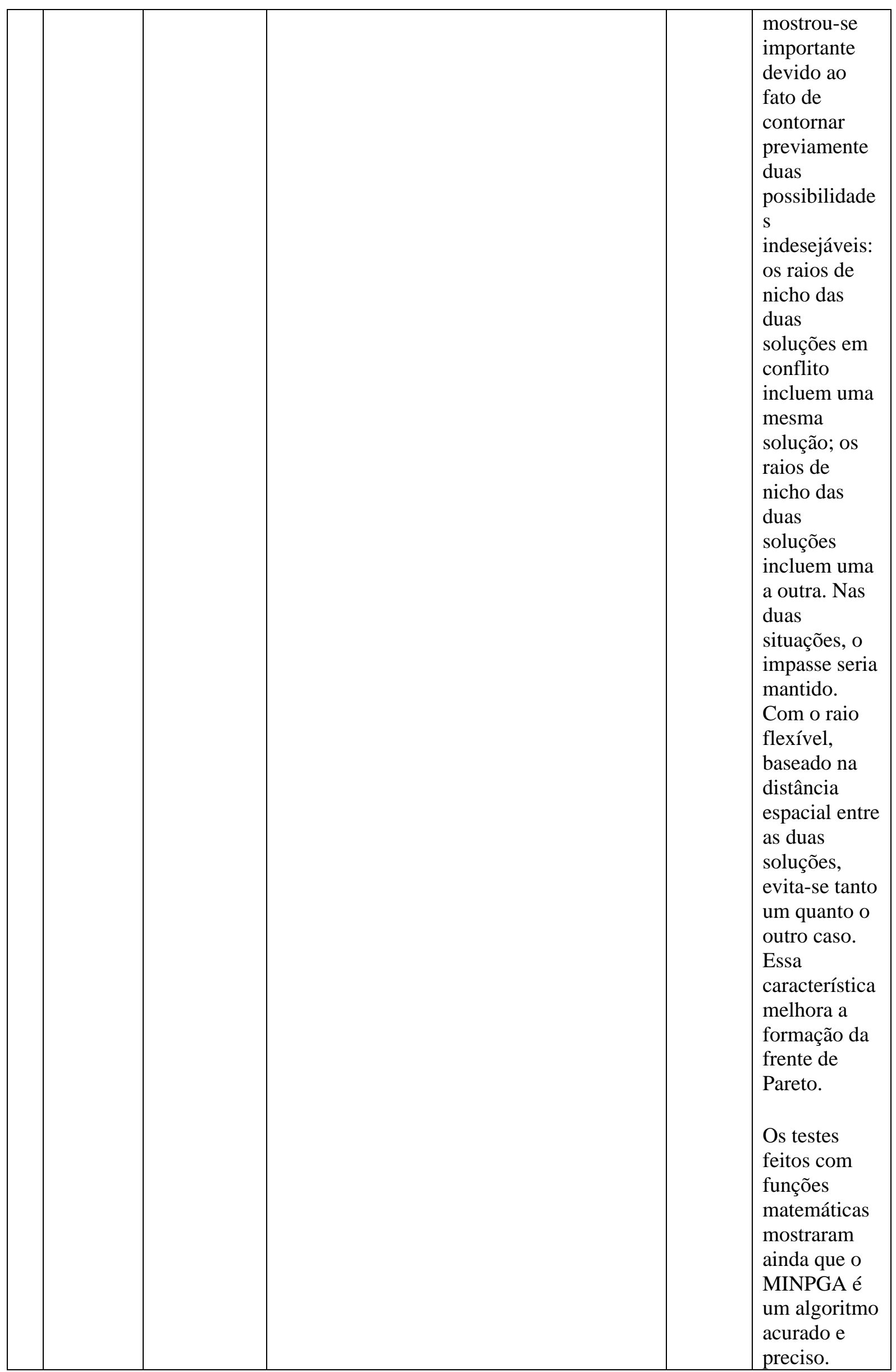




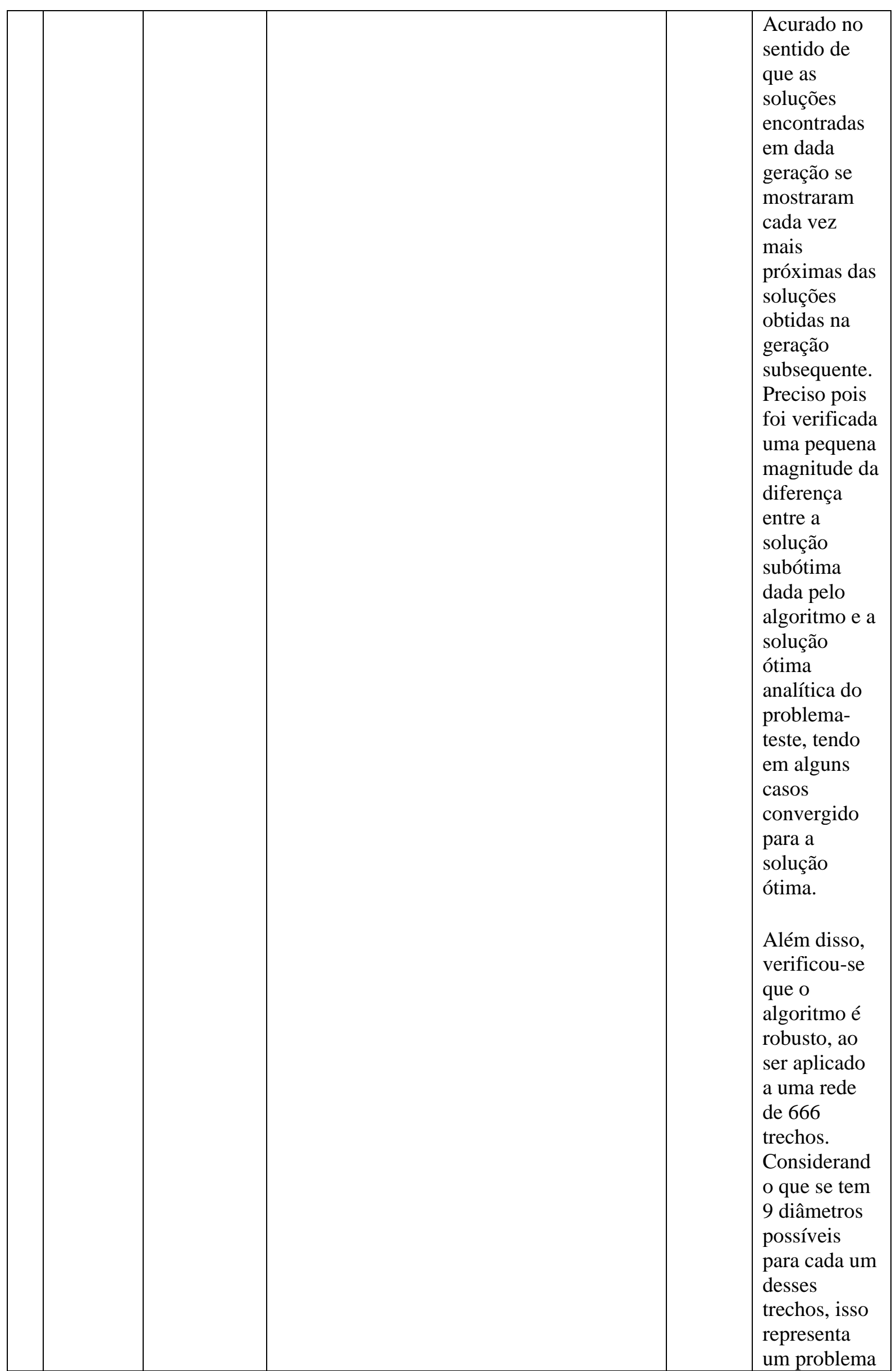




\begin{tabular}{|c|c|c|c|c|c|}
\hline & & & & & $\begin{array}{l}\text { de } 6,73 \text { x } \\
10^{19} \text { combina } \\
\text { ções. Se cada } \\
\text { uma dessas } \\
\text { combinações } \\
\text { pudesse ser } \\
\text { testada em } \\
\text { um } \\
\text { nanosegundo } \\
\text {, levar-se-ia } \\
\text { mais de } 2 \text { mil } \\
\text { anos para } \\
\text { concluir o } \\
\text { processo. } \\
\text { Isso mostra } \\
\text { que a } \\
\text { aplicação do } \\
\text { MINPGA é } \\
\text { adequada ao } \\
\text { problema e } \\
\text { oferece boas } \\
\text { soluções em } \\
\text { um tempo } \\
\text { razoável. }\end{array}$ \\
\hline 3 & \begin{tabular}{|l} 
Daniel \\
Manzi \\
Thaisa \\
Dias de \\
Castro \\
Goulart \\
\\
Bruno \\
Melo \\
Brentan \\
\\
Gustavo \\
Meirelle \\
s Lima \\
\\
Edevar \\
Luvizott \\
o Junior
\end{tabular} & $\begin{array}{l}\text { Dimension } \\
\text { amento } \\
\text { ótimo de } \\
\text { redes de } \\
\text { distribuição } \\
\text { de água } \\
\text { com uso de } \\
\text { métodos de } \\
\text { otimização } \\
\text { inspirados } \\
\text { na natureza }\end{array}$ & $\begin{array}{l}\text { http://revistadae.com.br/artigos/artigo_edic } \\
\text { ao_212_n_1735.pdf }\end{array}$ & $\begin{array}{l}13 / 09 / \\
2017\end{array}$ & $\begin{array}{l}\text { Dada a } \\
\text { natureza } \\
\text { irrestrita dos } \\
\text { métodos } \\
\text { heurísticos, } \\
\text { há } \\
\text { necessidade } \\
\text { de } \\
\text { penalização } \\
\text { da função } \\
\text { objetivo para } \\
\text { atendimento } \\
\text { às restrições } \\
\text { físicas do } \\
\text { problema. Os } \\
\text { resultados } \\
\text { obtidos } \\
\text { demonstram } \\
\text { que há } \\
\text { influência } \\
\text { significativa } \\
\text { da função de } \\
\text { penalização } \\
\text { para o } \\
\text { resultado } \\
\text { final, em } \\
\text { termos de } \\
\text { custo e }\end{array}$ \\
\hline
\end{tabular}




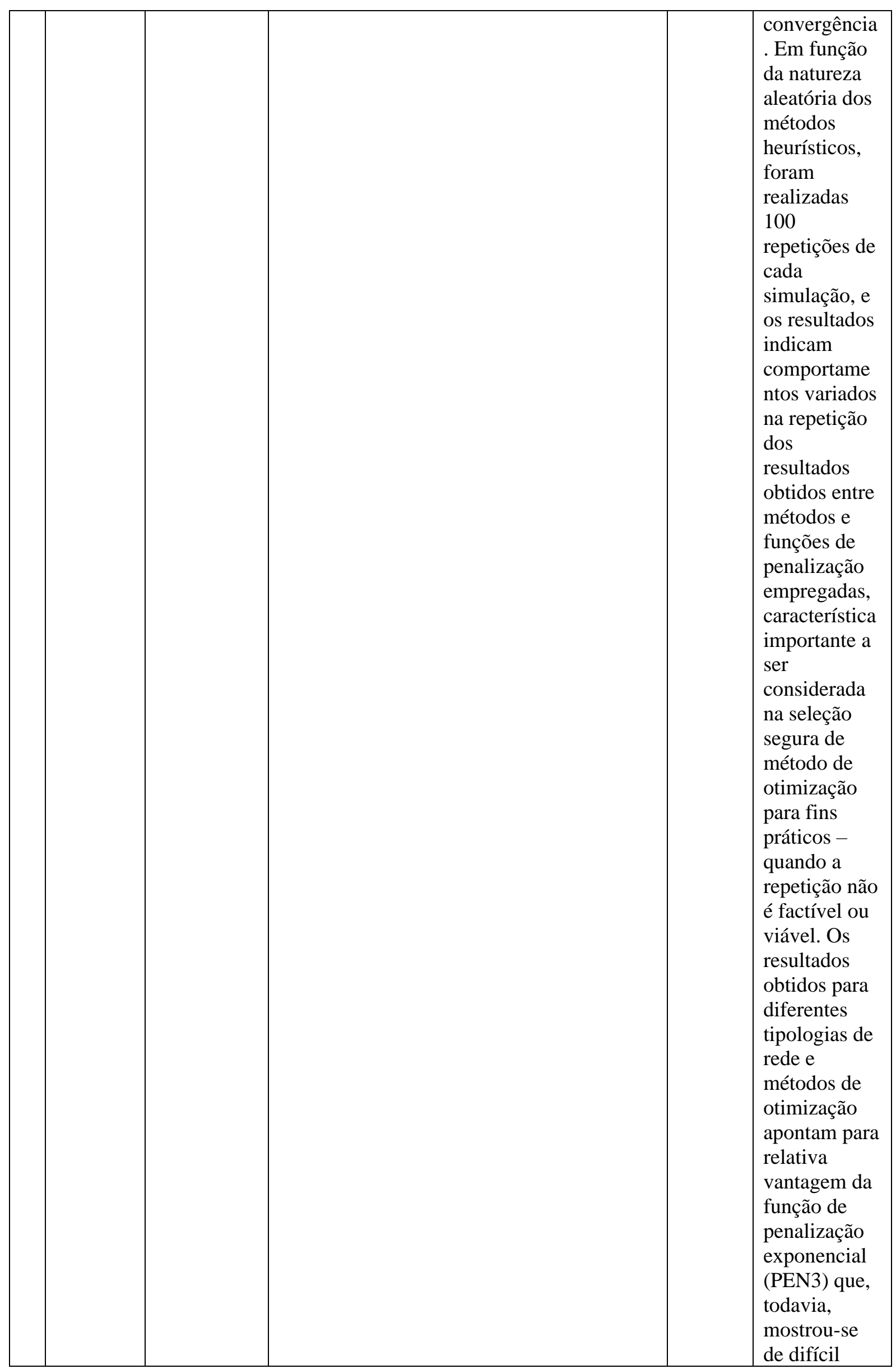




\begin{tabular}{|c|c|c|c|c|c|}
\hline & & & & & $\begin{array}{l}\text { aplicação em } \\
\text { alguns casos, } \\
\text { como para a } \\
\text { rede Hanoi. } \\
\text { A mesma } \\
\text { análise com } \\
\text { relação aos } \\
\text { métodos de } \\
\text { otimização } \\
\text { empregados } \\
\text { revela } \\
\text { desempenhos } \\
\text { ora } \\
\text { vantajosos, } \\
\text { ora } \\
\text { desvantajoso } \\
\text { s para cada } \\
\text { método em } \\
\text { função da } \\
\text { tipologia de } \\
\text { rede e função } \\
\text { de } \\
\text { penalização, } \\
\text { porém com } \\
\text { presença do } \\
\text { ABC e do } \\
\text { SLC entre os } \\
\text { melhores } \\
\text { resultados } \\
\text { em todas as } \\
\text { aplicações } \\
\text { realizadas. }\end{array}$ \\
\hline 4 & $\begin{array}{l}\text { Gustavo } \\
\text { Meirelle } \\
\text { s Lima } \\
\text { Bruno } \\
\text { Melo } \\
\text { Brentan } \\
\text { Antonio } \\
\text { Carlos } \\
\text { Zuffo } \\
\text { Edevar } \\
\text { Luvizott } \\
\text { o Junior }\end{array}$ & $\begin{array}{l}\text { Dimension } \\
\text { amento de } \\
\text { redes de } \\
\text { distribuição } \\
\text { de água por } \\
\text { meio de } \\
\text { análise } \\
\text { multicriteri } \\
\text { al }\end{array}$ & $\begin{array}{l}\text { http://revistadae.com.br/artigos/artigo_edic } \\
\text { ao_221_n_1831.pdf }\end{array}$ & $\begin{array}{l}27 / 06 / \\
2018\end{array}$ & $\begin{array}{l}\text { Atualmente, } \\
\text { diversos } \\
\text { trabalhos têm } \\
\text { focado no } \\
\text { dimensionam } \\
\text { ento de redes } \\
\text { de } \\
\text { abasteciment } \\
\text { o de água } \\
\text { apenas em } \\
\text { seu custo de } \\
\text { implantação. } \\
\text { Entretanto, } \\
\text { esse conceito } \\
\text { não leva em } \\
\text { conta outros } \\
\text { fatores } \\
\text { importantes, } \\
\text { e, em longo } \\
\text { prazo, essa } \\
\text { alternativa } \\
\text { pode se } \\
\text { mostrar }\end{array}$ \\
\hline
\end{tabular}




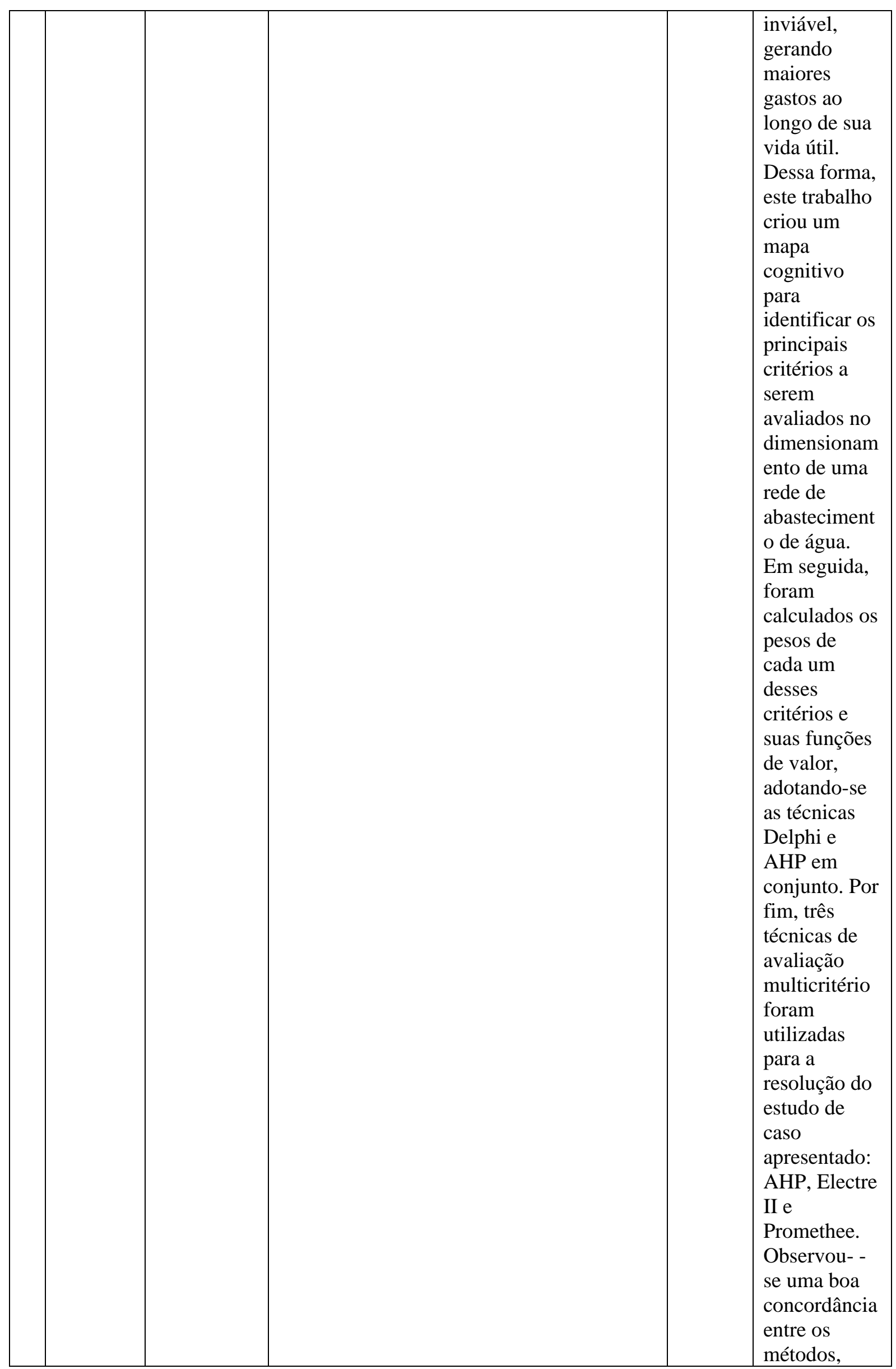




\begin{tabular}{|c|c|c|c|c|c|}
\hline & & & & & $\begin{array}{l}\text { demonstrand } \\
\text { o sua } \\
\text { aplicabilidad } \\
\text { e nesse tipo } \\
\text { de problema. } \\
\text { No estudo de } \\
\text { caso } \\
\text { apresentado, } \\
\text { devido aos } \\
\text { pesos e às } \\
\text { funções de } \\
\text { valor } \\
\text { adotadas, a } \\
\text { melhor } \\
\text { alternativa } \\
\text { coincidiu } \\
\text { com a de } \\
\text { menor custo. } \\
\text { Entretanto } \\
\text { esse } \\
\text { resultado é } \\
\text { dependente } \\
\text { do } \\
\text { julgamento } \\
\text { dos decisores } \\
\text { ao } \\
\text { determinare } \\
\text { m os pesos } \\
\text { dos critérios } \\
\text { e suas } \\
\text { funções de } \\
\text { valor, sendo } \\
\text { o resultado } \\
\text { final o } \\
\text { reflexo dos } \\
\text { interesses } \\
\text { prioritários } \\
\text { de cada } \\
\text { sistema. }\end{array}$ \\
\hline 5 & \begin{tabular}{|l}
$\begin{array}{l}\text { Erich Ke } \\
\text { llner }\end{array}$ \\
Jorge Ak \\
utsu \\
\\
Luisa \\
Fernand \\
a \\
Ribeiro \\
Reis
\end{tabular} & $\begin{array}{l}\text { Avaliação } \\
\text { da } \\
\text { rugosidade } \\
\text { relativa dos } \\
\text { tubos de } \\
\text { PVC com } \\
\text { vistas ao } \\
\text { dimensiona } \\
\text { mento das } \\
\text { redes de } \\
\text { distribuição } \\
\text { de água }\end{array}$ & $\begin{array}{l}\text { https://www.scielo.br/scielo.php?script=sci } \\
\text { arttext\&pid=S1413- } \\
41522016000200347 \& \operatorname{lng}=\text { pt\&tlng=pt }\end{array}$ & $\begin{array}{l}20 / 06 / \\
2016\end{array}$ & $\begin{array}{l}\text { As } \\
\text { tubulações } \\
\text { em PVC } \\
\text { (marrom) } \\
\text { com DN 50, } \\
75 \text { e } 100, \\
\text { novas, } \\
\text { apresentaram } \\
\text { rugosidade } \\
\text { média } \\
\text { variável de } \\
5,31 \pm 0,78 \mu \mathrm{m} \\
\text { a } \\
30,95 \pm 3,71 \mu \\
\text { m. }\end{array}$ \\
\hline
\end{tabular}




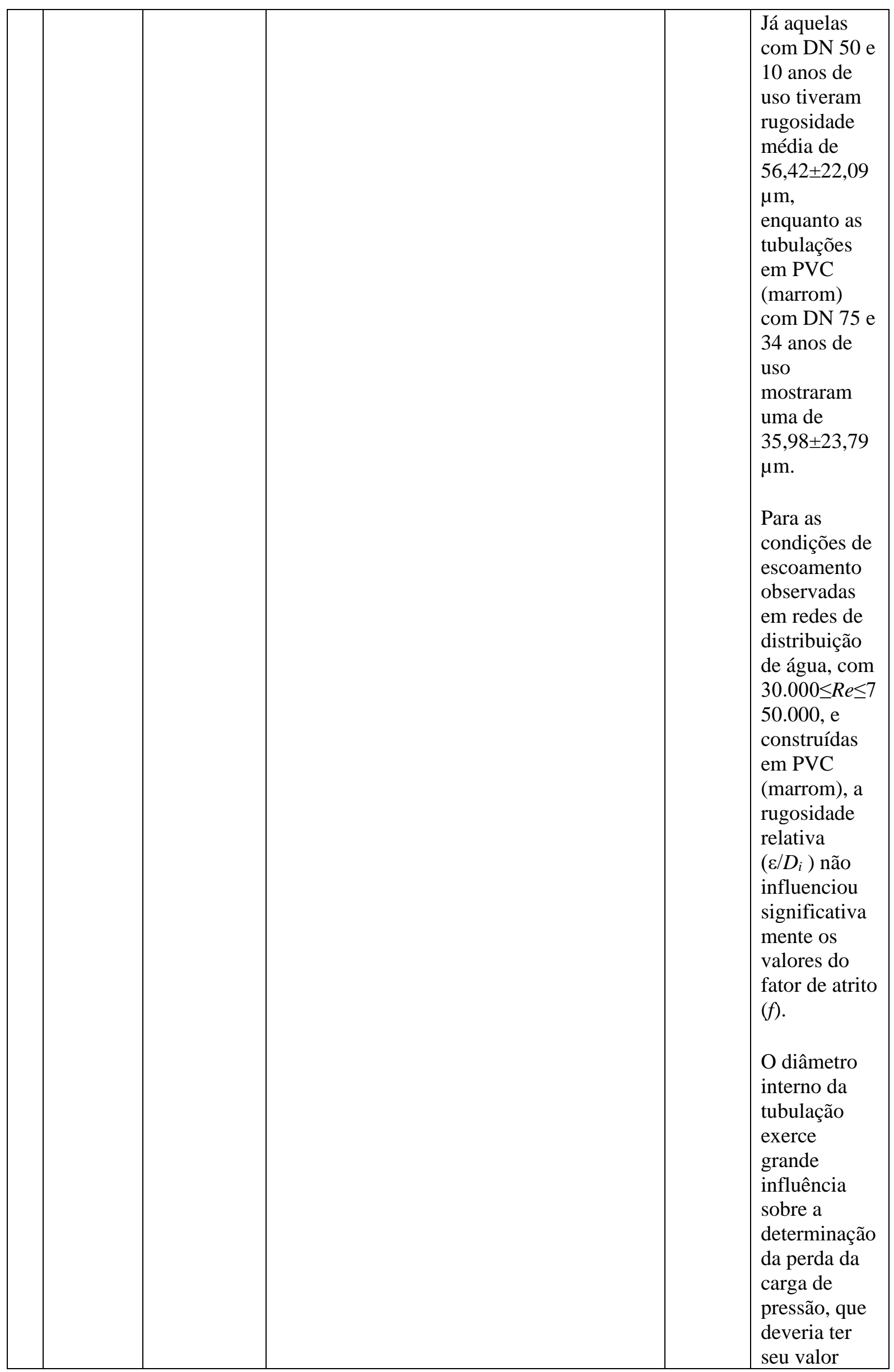




\begin{tabular}{|c|c|c|c|c|c|}
\hline & & & & & $\begin{array}{l}\text { mais } \\
\text { provável } \\
\text { estabelecido } \\
\text { pela } \\
\text { Associação } \\
\text { Brasileira de } \\
\text { Normas } \\
\text { Técnicas, } \\
\text { quando da } \\
\text { revisão da } \\
\text { NBR 5647- } \\
\text { 3:1999. }\end{array}$ \\
\hline 66 & \begin{tabular}{|l} 
Alex \\
Takeo \\
Yasumur \\
a \\
Lima Sil \\
va \\
\\
Fernand \\
o das \\
Graças \\
Braga \\
da Silva \\
\\
André \\
Carlos \\
da Silva \\
\\
José \\
Antonio \\
Tosta \\
dos Reis \\
\\
Claudio \\
Lindemb \\
erg \\
de Freita \\
s \\
Victor \\
Eduardo \\
de \\
Mello V \\
alério
\end{tabular} & $\begin{array}{l}\text { Proposição } \\
\text { de } \\
\text { estratégia } \\
\text { operacional } \\
\text { ótima } \\
\text { aplicada a } \\
\text { rede de } \\
\text { distribuição } \\
\text { de água } \\
\text { com } \\
\text { abordagem } \\
\text { estatistica }\end{array}$ & $\begin{array}{l}\text { https://www.scielo.br/scielo.php?script=sci } \\
\text { arttext\&pid=S1980- } \\
\text { 993X2020000200304\&lang=pt }\end{array}$ & $\begin{array}{l}09 / 04 / \\
2020\end{array}$ & $\begin{array}{l}\text { The genetic } \\
\text { algorithm of } \\
\text { optimization } \\
\text { obtained a } \\
\text { good } \\
\text { performance, } \\
\text { being able to } \\
\text { maintain } \\
\text { pressures } \\
\text { within } \\
\text { established } \\
\text { limits in the } \\
\text { study and } \\
\text { indicated the } \\
\text { quantity of } \\
\text { pumps and } \\
\text { valves } \\
\text { employed, as } \\
\text { well as } \\
\text { pumping } \\
\text { pressures or } \\
\text { the head loss } \\
\text { generated by } \\
\text { the valves } \\
\text { and portions } \\
\text { of pumps and } \\
\text { valve } \\
\text { implantation. } \\
\text { Thus, the } \\
\text { planning of } \\
\text { experiments } \\
\text { proved to be } \\
\text { a potential } \\
\text { tool to assist } \\
\text { in the } \\
\text { operation } \\
\text { optimization } \\
\text { of a water } \\
\text { distribution } \\
\text { network, } \\
\text { making } \\
\text { possible } \\
\text { optimization }\end{array}$ \\
\hline
\end{tabular}




\begin{tabular}{|c|c|c|c|c|c|}
\hline & & & & & $\begin{array}{l}\text { of the } \\
\text { equation of } \\
\text { obtained } \\
\text { response } \\
\text { surface and, } \\
\text { consequently } \\
\text {, obtention of } \\
\text { optimal } \\
\text { parameters } \\
\text { and } \\
\text { evaluation of } \\
\text { interactions. } \\
\text { However, } \\
\text { more studies } \\
\text { should be } \\
\text { done to } \\
\text { evaluate } \\
\text { performance } \\
\text { on more } \\
\text { complex and } \\
\text { real network } \\
\text { scenarios to } \\
\text { validate the } \\
\text { tool under } \\
\text { different } \\
\text { conditions. }\end{array}$ \\
\hline 77 & $\begin{array}{l}\text { Danielle } \\
\text { Costa } \\
\text { Morais } \\
\\
\text { Cristiano } \\
\text { A. } \\
\text { Virgínio } \\
\text { Cavalca } \\
\text { nte } \\
\\
\text { Adiel } \\
\text { Teixeira } \\
\text { de } \\
\text { Almeida }\end{array}$ & $\begin{array}{l}\text { Priorização } \\
\text { de áreas de } \\
\text { controle de } \\
\text { perdas em } \\
\text { redes de } \\
\text { distribuição } \\
\text { de água }\end{array}$ & $\begin{array}{l}\text { https://www.scielo.br/scielo.php?script=sci } \\
\text { arttext\&pid=S0101- } \\
74382010000100002 \& \text { lang=pt }\end{array}$ & $\begin{array}{l}04 / 201 \\
0\end{array}$ & $\begin{array}{l}\text { Neste } \\
\text { trabalho, foi } \\
\text { apresentado } \\
\text { um modelo } \\
\text { multicritério } \\
\text { baseado no } \\
\text { método } \\
\text { PROMETHE } \\
\text { E I para a } \\
\text { priorização } \\
\text { das áreas } \\
\text { críticas de } \\
\text { perdas de } \\
\text { uma cidade, } \\
\text { dentro de } \\
\text { uma } \\
\text { avaliação } \\
\text { global, de } \\
\text { uma forma } \\
\text { balanceada } \\
\text { com os } \\
\text { critérios } \\
\text { preestabeleci } \\
\text { dos, } \\
\text { orientando } \\
\text { para uma } \\
\text { alocação de } \\
\text { investimento } \\
\text { de tempo e }\end{array}$ \\
\hline
\end{tabular}




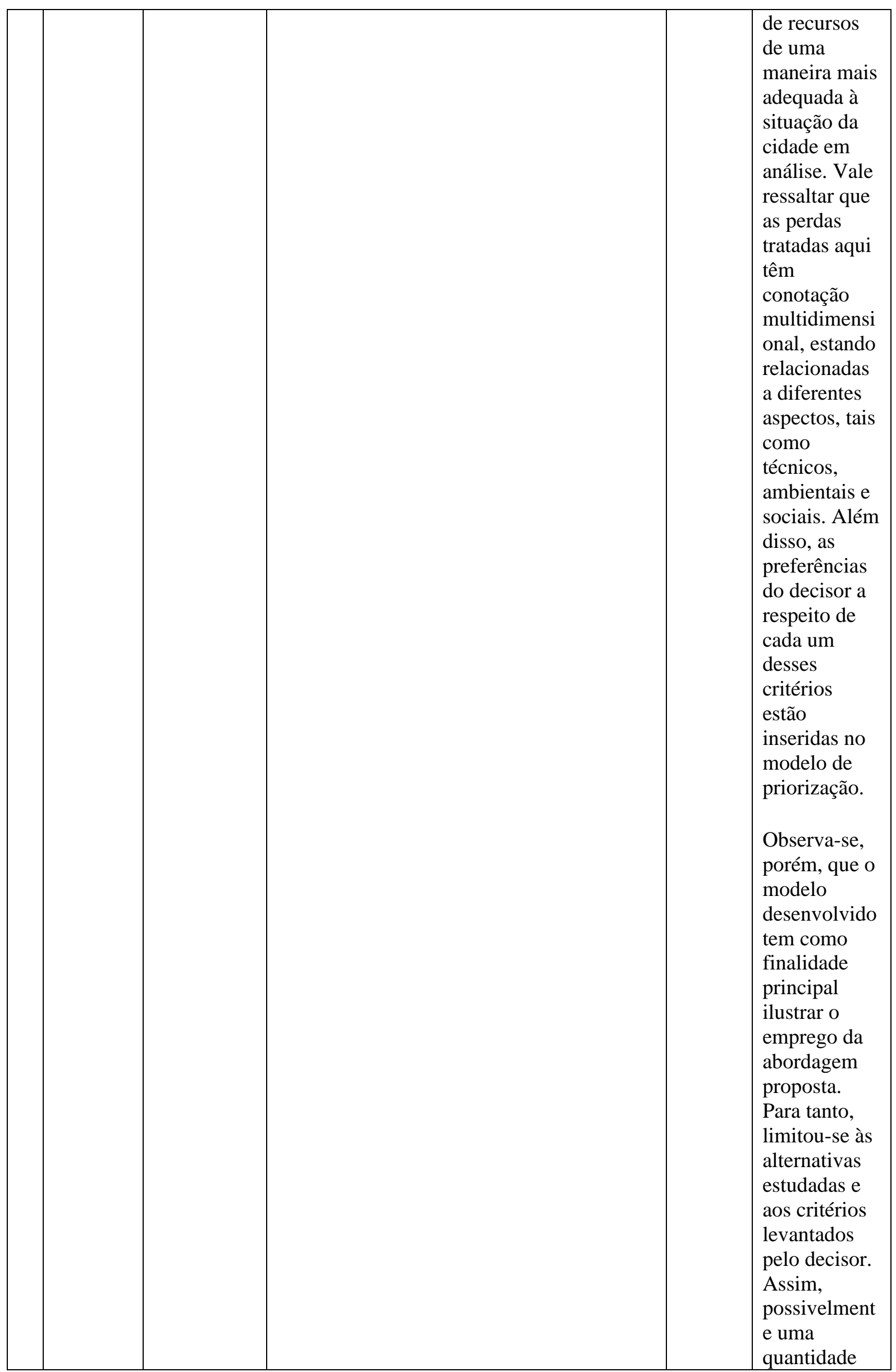




\begin{tabular}{|c|c|c|c|c|c|}
\hline & & & & & $\begin{array}{l}\text { mais } \\
\text { significativa } \\
\text { de critérios } \\
\text { poderia ter } \\
\text { sido } \\
\text { considerada } \\
\text { na análise, o } \\
\text { que } \\
\text { obviamente } \\
\text { modificaria o } \\
\text { seu resultado } \\
\text { final. Além } \\
\text { disso, } \\
\text { observa-se } \\
\text { que, apesar } \\
\text { de o modelo } \\
\text { ter sido } \\
\text { aplicado para } \\
\text { uma cidade } \\
\text { de pequeno } \\
\text { porte, ajusta- } \\
\text { se } \\
\text { perfeitament } \\
\text { e a } \\
\text { problemas } \\
\text { semelhantes, } \\
\text { que } \\
\text { envolvem } \\
\text { grandes } \\
\text { cidades. }\end{array}$ \\
\hline 8 & \begin{tabular}{|l} 
Fátima \\
C. \\
Soares \\
Guilher \\
me C. \\
Teles \\
\\
Jumar L. \\
Russi
\end{tabular} & $\begin{array}{l}\text { Aferição } \\
\text { dos Valores } \\
\text { dos } \\
\text { Comprimen } \\
\text { tos } \\
\text { Equivalente } \\
\text { s Utilizados } \\
\text { na } \\
\text { Determinaç } \\
\text { ão da Perda } \\
\text { de Carga }\end{array}$ & $\begin{array}{l}\text { http://www.scielo.org.ar/scielo.php?script= } \\
\text { sci_arttext\&pid=S1851- } \\
\text { 75872015000200003\&lang=pt }\end{array}$ & $\begin{array}{l}03 / 07 / \\
2015\end{array}$ & $\begin{array}{l}\text { De acordo } \\
\text { com a } \\
\text { metodologia } \\
\text { utilizada e } \\
\text { nas } \\
\text { condições em } \\
\text { que o } \\
\text { trabalho foi } \\
\text { realizado } \\
\text { pode-se } \\
\text { concluir: } \\
\text { Os valores } \\
\text { adotados } \\
\text { como } \\
\text { comprimento } \\
\text { s } \\
\text { equivalentes, } \\
\text { apresentados } \\
\text { pela } \\
\text { literatura, } \\
\text { geram perdas } \\
\text { de carga } \\
\text { localizada, } \\
\text { em cotovelo } \\
\text { de } 45^{\circ} \text { e } 90^{\circ}\end{array}$ \\
\hline
\end{tabular}




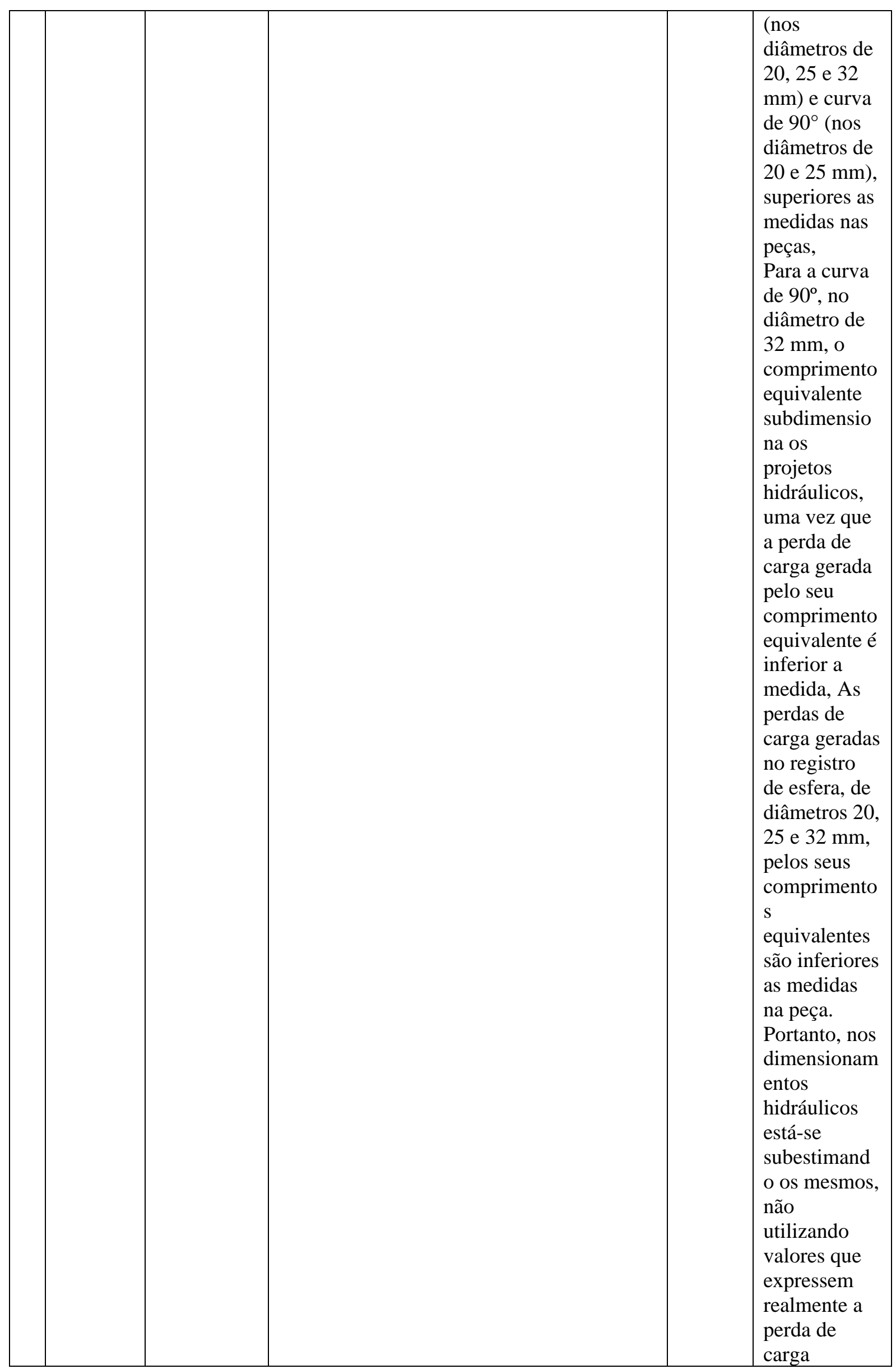




\begin{tabular}{|l|l|l|l|}
\hline & & & \\
& & & $\begin{array}{l}\text { causada por } \\
\text { essas } \\
\text { singularidade } \\
\text { s, } \\
\text { acarretando } \\
\text { em erros nos } \\
\text { projetos de } \\
\text { instalações } \\
\text { hidráulicas, } \\
\text { podendo } \\
\text { assim } \\
\text { comprometer } \\
\text { a eficiência } \\
\text { das mesmas, } \\
\text { visto que } \\
\text { essas peças } \\
\text { são de uso } \\
\text { frequente, }\end{array}$ \\
\hline
\end{tabular}

Fonte: elaborada pelos autores.

O corpo textual foi analisado por meio da frequência de palavras, que originou a nuvem de palavras (Figura 1) criada na Plataforma online WordArt. Esta ferramenta agrupa e organiza graficamente as palavras-chave evidenciando-as as mais frequentes.

Figura 1 - Nuvem de palavras organizada na plataforma online do WordArt com base nas conclusões dos artigos contidos no Quadro 3.

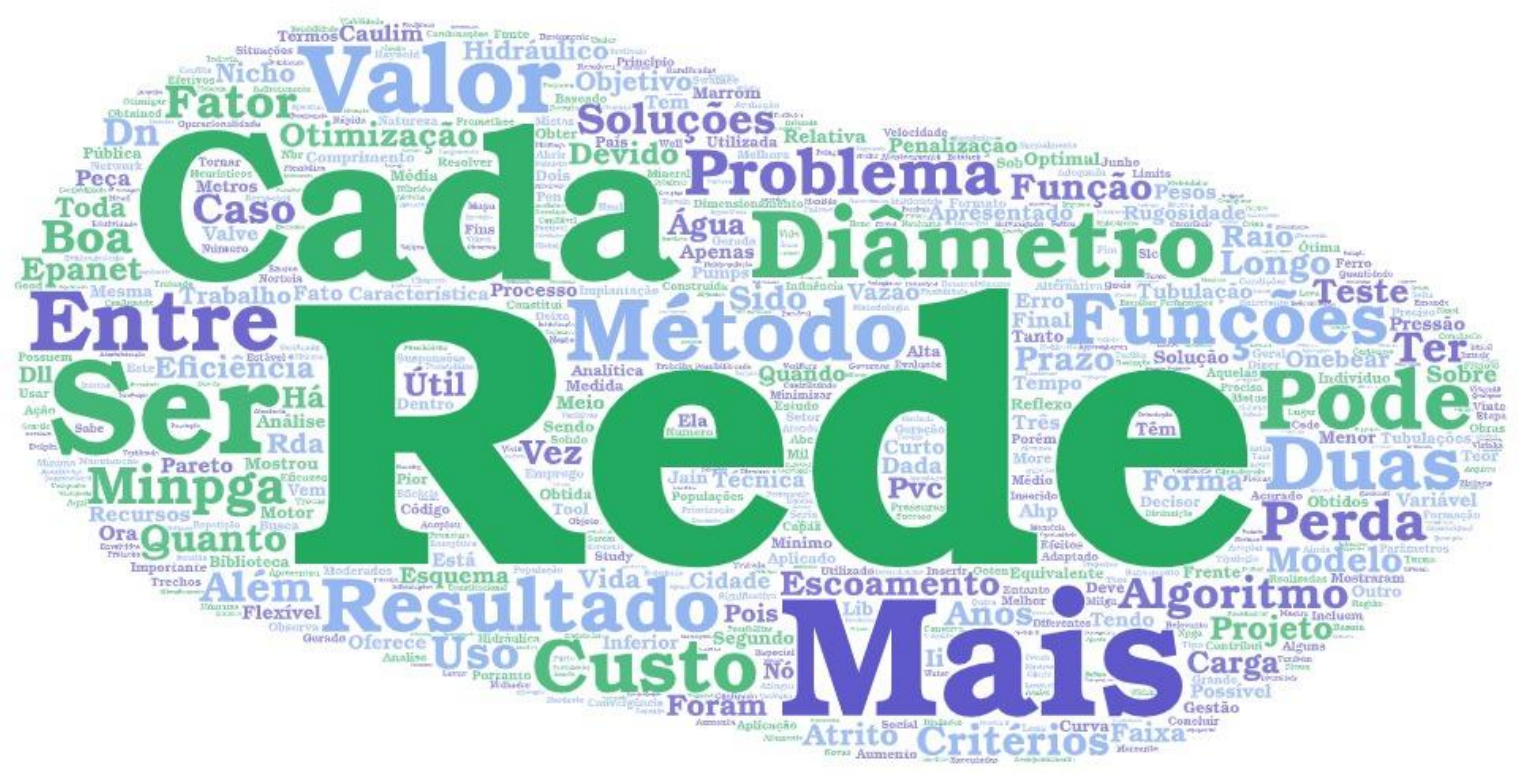

Fonte: elaborada pelos autores. 
Por meio da Figura 1, foi possível observar que as palavras em evidência na nuvem pertencem as categorias desenvolvidas a partir da análise de conteúdo. Todas as categorias derivam da sua frequência (Tabela 1), que diz respeito ao seu quadro referencial. Em consonância ao objetivo deste trabalho, optou-se por descrever as palavras que apresentaram frequência total no texto.

Tabela 1. Frequência das palavras presentes nos textos publicados nas Plataformas....

\begin{tabular}{l|c|l}
\hline \multicolumn{1}{c|}{ PALAVRAS } & FREQUÊNCIA & \multicolumn{1}{c}{ CATEGORIAS } \\
\hline Rede & 18 & Rede de abastecimento/distribuição \\
\hline Perda & 7 & Perda de carga \\
\hline Diâmetro & 10 & Diâmetro das tubulações \\
\hline Otimização & 6 & Otimização do projeto \\
\hline Método & 9 & Métodos para minimização de erros \\
\hline
\end{tabular}

Fonte: elaborada pelos autores.

\section{Discussões}

Atualmente, diversos trabalhos têm sido desenvolvidos na área de dimensionamento de redes de abastecimentos de águas, com o intuito de otimizar tanto o processo de dimensionamento quanto os cálculos de perdas de carga nas tubulações. Quanto maior a proporção de alcance da rede de distribuição, seu tempo de uso e a topografia a ser dimensionada, maior será a dificuldade de um dimensionamento reduzindo ao máximo o custo do investimento e otimizando o projeto a ponto de pouca ou nenhuma observação ser feita com relação a melhorias.

São muitos os fatores a serem analisados para a obtenção de um projeto onde é maximizado o custo/benefício da obra, para isso, o conhecimento dos fatores influenciadores na rede de distribuição é de suma importância. Em projetos relativamente extensos os erros tendem a ser superdimensionados ou subdimensionados, o que causam perdas de recursos, necessidade de mais mão de obra para refazer o serviço (quando possível ser realizado) e transtorno para todos os envolvidos.

Os fatores como: local de capitação, topografia do terreno, extensão do dimensionamento, pressão de captação e de fornecimento, vazão a ser fornecida, diâmetro das tubulações, rugosidade do material, tempo de uso, entre outros, são 
determinantes para a obtenção de um projeto otimizado.

Os trabalhos analisados usam de vários recursos como: programas computacionais, fórmulas disponibilizadas nas Normas Brasileiras e nas literaturas, experimento de campo com o propósito de facilitar o entendimento do dimensionamento de redes de abastecimento de águas e tornar o empreendimento mais seguro e rentável, oferecendo ao investidor um retorno confiável e duradouro.

Cada um dos trabalhos converge para uma importante observação que é o reconhecimento da necessidade de um projeto específico para cada situação. Porém, há elementos que permanecem presentes em todos os projetos, e especificamente são esses que conhecimento prévio do comportamento ajudará para uma melhor otimização da maioria dos projetos hidráulicos.

Elementos como; cano de PVC, de ferro, joelho de 45 e $90^{\circ}$, curvas, redutores, válvulas, entre outros mais, são diretamente influenciadores de perdas de carga, diminuição de velocidade de condução, desgaste do elemento usado no dimensionamento o que gerará uma diminuição da vida de uso do material. Cada um desses elementos possui um comprimento equivalente, que é entendido como a perda de carga localizada e distribuída nas tubulações. O estudo do comprimento equivalente (Leq) de cada um dos elementos que fará parte do dimensionamento da rede de distribuição será essencial para manter a pressão interna do fluído conforme o planejado, consequentemente a vazão e vida útil do material será próximo ao determinado no projeto.

Conforme concluíram, Soares; teles e Russi (2015), em seus estudos sobre a verificação do uso de comprimento equivalente em cálculos de perdas de cargas, foi que os valores que são disponibilizados pela literatura referente a elementos com perdas de cargas localizadas são superiores a medidas reais. Essa constatação foi aferida nas peças de curva de $90^{\circ}$ (diâmetros de 20 e $25 \mathrm{~mm}$ ) e em cotovelos de 45 e $90^{\circ}$ (diâmetros de 20, 25 e $32 \mathrm{~mm}$ ). Outra observação verificada foi que o comprimento equivalente determinado para o registro esfera, nos diâmetros de 20, 25 e $32 \mathrm{~mm}$, estava muito abaixo do real, ou seja, a perda de carga é muito maior do valor que estava se estimando.

Outra verificação muito importante feita por Kelner; Akutsu e Ribeiro (2016) quando estudado a relação da rugosidade nos tubos de PVC com o objetivo do dimensionamento das redes de distribuição de água, foi que quanto menor o diâmetro das tubulações maior será o desgaste com o 
passar dos anos. Esse desgaste ocorre devido a velocidade do fluido ser muito maior em diâmetros menores.

Por esses pontuais fatores observase que o dimensionamento de uma rede de distribuição, com vista na otimização completa do projeto é algo muito complexo, e por isso, o conhecimento de programas computacionais é de suma importância para diminuição da complexidade e para reduzir possíveis erros quando dimensionado de maneira manual.

Dentre os artigos analisados um algoritmo chamado de EPANET é o mais usual para facilitar o dimensionamento. Segundo o trabalho de Takeo et al., (2020) o programa apresentou um desempenho satisfatório, sendo capaz de estabelecer as pressões dentro do limite estudado e ainda indicando a quantidade de bombas e válvulas a serem empregadas.

Claro que um projeto de dimensionamento, como dito anteriormente, quanto maior a dimensão de alcance desejado, maior será sua

\section{CONCLUSÕES}

\begin{abstract}
Em suma, o presente artigo apresenta os diversos fatores que influenciam as perdas de cargas existentes nas redes de distribuição de água, esses trazem consigo insatisfação à população,
\end{abstract}

complexidade e consequentemente será impossível resolver todos os problemas da rede. Com isso, verifica-se que existe a possibilidade de erros de projeto, o que ocasionara possíveis rompimentos de tubulações e consequente perdas de água, danos ao meio ambiente e transtorno para a população próxima. Levando isso em consideração, existem métodos para analisar locais específicos que geraria esses possíveis erros, sendo assim chamados de critérios de avaliação, onde é determinado qual local a ser executado deverá receber maior atenção. Um dos métodos que tem tido preferência é o PROMETHEE (Preference Ranking Organization Method for Envrichment Evaluation), como o próprio nome revela, o método estabelece um ranking de critérios dando ao executador a possibilidade de minimizar os possíveis erros, garantindo assim a otimização do projeto. Segundo Costa; Virginio e Texeira (2010) esse método se mantem satisfatório tanto para projetos de pequeno quanto de grandes portes.

impactos ambientais e custos elevados para executar e/ou fazer manutenções.

Contudo, a partir dos resultados obtidos e visando minimizar as perdas de cargas, faz-se necessário ampliar os estudos para melhoria dos projetos hidrossanitários e recursos para execução, desde a captação até a distribuição. 
Logo, concluímos que para otimizar os projetos é recomendado usar programas computacionais com intuito de reduzir ao

\section{REFERÊNCIAS}

SOARES, F.; TELES, G.; RUSSI, J. Aferição dos Valores dos Comprimentos Equivalentes Utilizados na Determinação da Perda de Carga. Revista de Ciencia y Tecnología, n. 24, p. 16-21, 2015.

PINNTO, M. R. et al. Dimensionamento econômico otimizado de redes de distribuição de água considerando custos de manutenção. Engenharia Sanitaria e Ambiental, v. 22, n. 1, p. 145-153, 2017.

MANZI, D. et al. Dimensionamento ótimo de redes de distribuição de água com uso de métodos de otimização inspirados na natureza. Revista DAE, v. 66, n. 212, p. 1631, 2018.

MELO BRENTAN, B. et al. Dimensionamento de redes de distribuição de água por meio de análise multicriterial. Revista DAE, v. 221, n. 68, p. 118-130, 2019.

KELLNER, E.; AKUTSU, J.; REIS, L. F. R. Avaliação da rugosidade relativa dos tubos de PVC com vistas ao dimensionamento das redes de distribuição máximo os possíveis erros de projetos de redes de distribuição.

de água. Engenharia Sanitaria e Ambiental, v. 21, n. 2, p. 347-355, 2016.

SILVA, A.; DA SILVA, F.; DA SILVA, A. Proposal of optimal operation strategy applied to water distribution network with statistical approach. Revista Ambiente e Água, (2020), 15(2) Disponível em: Proposal of optimal operation strategy applied to water distribution network with statistical approach (scielo.br).

MORAIS, D. C.; CAVAlCANTE, C. A. V.; DE ALMEIDA, A. T. Priorização de áreas de controle de perdas em redes de distribuição de água. Pesquisa Operacional, v. 30, n. 1, p. 15-32, 2010.

NOVARINI, B. et al. Gerenciamento de pressão ideal em redes de distribuição de água por meio da criação de área distrital medida com base em aprendizado de máquina. Revista Brasileira de Recursos Hidricos, v. 24, p. 1-11, 2019.

Brasil. Fundação Nacional de Saúde. Manual de Orientações Funasa. - Brasília: Funasa, 2017.

SILVA, F. D. B.; O. O Sistema De Abastecimento D' Água Da Cidade De Santa Rita - Pb. 2016. 